\title{
Serafino Zappacosta: An Enlightened Mentor and Educator
}

\author{
Ennio Carbone ${ }^{1,2}$, Mario De Felice ${ }^{3}$, Francesca Di Rosa ${ }^{4 *}$, Ugo D'Oro ${ }^{5}$, Silvia Fontana ${ }^{3}$, \\ Antonio La Cava ${ }^{6}$, Michele Maio ${ }^{7}$, Giuseppe Matarese ${ }^{3,8}$, Luigi Racioppi ${ }^{8,9}$, \\ Giuseppina Ruggiero ${ }^{10 *}$ and Giuseppe Terrazzano ${ }^{10,11}$
}

${ }^{1}$ Department of Experimental and Clinical Medicine, University "Magna Graecia" of Catanzaro, Catanzaro, Italy, ${ }^{2}$ Department of Microbiology, Cell and Tumor Biology, Karolinska Intitutet, Stockholm, Sweden, ${ }^{3}$ Istituto per l'Endocrinologia e l'Oncologia Sperimentale, Consiglio Nazionale delle Ricerche (IEOS-CNR), Naples, Italy, ${ }^{4}$ Institute of Molecular Biology and Pathology, Consiglio Nazionale delle Ricerche (IBPM-CNR), Rome, Italy, ${ }^{5}$ GlaxoSmithKline, Siena, Italy, ${ }^{6}$ Department of Medicine, University of California, Los Angeles, Los Angeles, CA, United States, ${ }^{7}$ Center for Immuno-Oncology, Medical Oncology and Immunotherapy, Department of Oncology, University Hospital of Siena, Siena, Italy, ${ }^{8}$ Dipartimento di Medicina Molecolare e Biotecnologie Mediche, Università degli Studi di Napoli "Federico II", Naples, Italy, ${ }^{9}$ Division of Hematological Malignancies and Cellular Therapy, Department of Medicine, Duke University School of Medicine, Durham, NC, United States,

${ }^{10}$ Dipartimento di Scienze Mediche Traslazionali, Università di Napoli "Federico II", Naples, Italy, " Dipartimento di Scienze, Università della Basilicata, Potenza, Italy

OPEN ACCESS

Edited by: Ivan Zanoni,

Harvard Medical School, United States

Reviewed by:

Francesca Granucci, University of Milano Bicocca, Italy

Diana Boraschi, Istituto di Biochimica Delle Proteine (IBP), Italy

*Correspondence: Francesca Di Rosa francesca.dirosa@cnr.it Giuseppina Ruggiero giruggie@unina.it

Specialty section: This article was submitted to

Molecular Innate Immunity, a section of the journal

Frontiers in Immunology

Received: 17 December 2019

Accepted: 27 January 2020

Published: 13 February 2020

Citation:

Carbone E, De Felice M, Di Rosa F, D'Oro U, Fontana S, La Cava A,

Maio M, Matarese G, Racioppi L, Ruggiero G and Terrazzano G (2020) Serafino Zappacosta: An Enlightened Mentor and Educator.

Front. Immunol. 11:217.

doi: 10.3389/fimmu.2020.00217
With this article, the authors aim to honor the memory of Serafino Zappacosta, who had been their mentor during the early years of their career in science. The authors discuss how the combination of Serafino Zappacosta's extraordinary commitment to teaching and passion for science created a fostering educational environment that led to the creation of the "Ruggero Ceppellini Advanced School of Immunology." The review also illustrates how the research on the $\mathrm{MHC}$ and the inspirational scientific context in the Zappacosta's laboratory influenced the authors' early scientific interests, and subsequent professional work as immunologists.

Keywords: education, MHC, T cells, NK cells, immune response

Serafino Zappacosta, the founder of the "Ruggero Ceppellini Advanced School of Immunology" (Ceppellini School), epitomized the term "mentor." This term was first used by François Fénelon in the book "Les Aventures de Télémaques" to define an enlightened educator who is endowed with unprejudiced knowledge and wisdom (1). The name came after Mentor, the guardian and educator of Odysseus' son Telemachus who offered him encouragement and support for dealing with personal dilemmas while his father was away fighting in the Trojan War. As a mentor and professor of immunology at the University of Naples "Federico II," Serafino Zappacosta communicated science to his students and close collaborators as a fascinating tool to constantly pursue and advance knowledge, thus nourishing their innate human eagerness to learn. The authors of this article had the privilege to be former members of Zappacosta's laboratory, and wish to offer him this posthumous tribute.

Serafino Zappacosta was a highly cultivated scientist, whose interests spanned from the classics to arts (2). His open-minded vision led him to go beyond the traditional approach to didactics toward new models of education. He conceptualized the idea of an international advanced school of immunology because of his recognition of the quintessential importance in committing educational efforts to nurturing generations of young researchers from all over the world, promoting exchanges between western world and developing countries. The Zappacosta's school model embraced an open and transparent communication that was instrumental to expand the creative potential of independent-minded young investigators, to foster their critical and analytical interests, and to channel their energies into highly valuable scientific directions. 
Serafino Zappacosta founded the Ceppellini School in 1991 together with Antonio Di Giacomo (Experimental Immunologist working at the Monaldi Hospital in Naples, Italy), Melchiorre Brai (Professor of Immunology at the University of Palermo, Italy), Giovan Battista Ferrara (Professor of Human Genetics at the Federico II University of Naples, Italy), Albert Nisonoff (Professor of Biology at Brandeis University, in Waltham, Massachusetts, USA), and Ciro Manzo (Head of Immunology Department at the Istituto Pascale in Naples, Italy). The choice of Naples as Ceppellini School headquarters was no accident. This city had experienced in 1799, during the Neapolitan Republic, an unsuccessful attempt to gain freedom from the constraints of a tyrannical monarchy, and to promote a new political organization. This attempt was brutally suppressed. The choice of Naples symbolically reflected the will to propel the freedom of scientific minds according to the School's motto "non multa sed multum" ("not many but much," i.e., quality rather than quantity) (3). Over the years, the Ceppellini School has been attracting and engaging large numbers of international young scientists to the field of immunology.

\section{FOCUSING ON MHC MOLECULES}

Serafino Zappacosta had a strong interest in the major histocompatibility complex (MHC) genes and proteins. He shared his fascination for the MHC with his laboratory members, with whom he investigated a variety of topics in the MHC field, including the regulation of HLA expression in tumor cells $(4,5)$, the association between HLA alleles and diseases in Southern Italy $(6,7)$, the influences of MHC class I (MHCI) on tumor killing by NK cells (8), and the cytokine-mediated regulation of MHC-I expression (9). His laboratory also worked in collaboration with many international teams to study HLA polymorphisms, and participated in collaborative workshops on HLA typing, that included the International Histocompatibility Workshop in 1991 in Yokohama, Japan (10). This interest in MHC also led to the name of the Ceppellini School, after the immuno-geneticist Ruggero Ceppellini, who had greatly contributed with his pioneer work to the understanding of the genetic bases of HLA polymorphisms, and coined the term "haplotype" (11).

\section{MHC POLYMORPHISM AND THE MEDITERRANEAN AREA}

Before molecular genetics could rely on modern technology to collect a tremendous amount of information, many data about the genetic background of different human populations were based on the analysis of products of polymorphic loci including HLA. Analyzing the HLA system at the end of the '70s, Zappacosta, together with Mario De Felice, Michele Fiore and Giovan Battista Ferrara (12), found significant differences between people living in Northern Italy and the population of Campania (in Southern Italy). Significant similarities were noticed between Mediterranean and Middle Eastern populations and people from Campania, confirming that the genetic background of the Italian population is highly mixed. Furthermore, a peculiar association between HLA alleles and congenital adrenal hyperplasia was found by Serafino Zappacosta, Michele Maio, Mario De Felice and Rossella Valentino in the Sothern Italian population (6). These studies were performed at the time when Luigi Cavalli-Sforza investigated the selection of advantageous alleles in HLA locus and other polymorphic loci, whereby those findings served to illustrate migration patterns of human populations (13).

Further studies on MHC polymorphism were performed over the years by Giuseppina Ruggiero, Giuseppe Matarese, Giuseppe Terrazzano, and others in the Zappacosta's laboratory. They demonstrated a link between HLA alleles and susceptibility to autoimmune/infectious diseases in Southern Italy $(7,14)$. Other Zappacosta's team members, including Michele Maio, Luigi Del Vecchio, and Mario De Felice, documented the association between HLA-DR alleles and thyroid carcinoma (15). In the 80, Michele Maio, Luigi Del Vecchio, Giuseppina Ruggiero, Mario De Felice and others of the Zappacosta's laboratory investigated MHC-I expression as a prognostic factor in breast cancer (5). Antonio Pinto, Michele Maio and others showed that HLADR expression by myeloid leukemia cells was modulated by anti-neoplastic drugs (4).

\section{MHC MOLECULES AND THE REGULATION OF NK CELL RESPONSE}

In the late '80, Silvia Fontana, Luigi Racioppi and Ennio Carbone in Zappacosta's team investigated the link between retroviral infection and MHC-I expression by tumor cells, using virusinduced rat thyroid adenocarcinomas as an experimental model $(16,17)$. At the time, state-of-the-art techniques for these studies included tissue culture, microscopy, immunofluorescence, and cytofluorimetry, that had only become available a few years earlier. Silvia Fontana, Ennio Carbone, and others in the team showed that tumor transformation modulated MHC-I expression by rat tumor cells, and that rat Large Granular Lymphocytes (LGL) killed more effectively tumor cells having low MHC-I expression (8). These observations were puzzling at that time. In 1987-just a few years before these studies-, Bjorkman and colleagues had solved the HLA A2 crystallographic structure (18, 19), and a lot of attention was concentrated on the TCR/MHCI molecular interaction, and its role in immunity. On the other hand, Ennio Carbone of the Zappacosta's team was fascinated by pioneering studies on the inhibitory signals provided by MHCI to Natural Killer (NK) cells [the "missing self" hypothesis, formulated by Klas Karre in 1981 (20)]. Together with Antonio La Cava, Giuseppe Terrazzano and others, the Zappacosta group's contributions to the NK field spanned from MHC-I mediated regulation of NK cell cytotoxicity in rat tumor models $(8,21)$, to NK cell inhibition induced by soluble HLA-I $(22)$, to new findings on the role of NK cells in human tumor immunosurveillance (23), NK/ dendritic cells cross-talk $(24,25)$, and CD1-mediated inhibition of NK cytotoxicity (26). Giuseppe Terrazzano in the group investigated the effects of IL-10 on MHC-I expression and on the antigen presenting machinery 
(9), demonstrating a pathological role of gliadin in the NK cell/ dendritic cells cross-talk (27). Sadly, this publication was the last one that included Serafino Zappacosta's co-authorship.

\section{MHC MOLECULES AND THE REGULATION OF T CELL RESPONSE}

In the early 90's, it was well-established that the function of MHC molecules was to bind and present antigenic peptides to $\mathrm{T}$ cells $(28,29)$. The molecular bases of this phenomenon had been largely resolved by several independent studies (30-35). However, looking out of this canonical box, it was possible to hypothesize that, in addition to binding TCR and CD4, MHC class II (MHC-II) molecules might also interact with other cell surface molecules, and in turn regulate the activation of immune cells. Within this context, Zappacosta's group aimed to identify non-canonical functions of HLA-II molecules (36-39). A large panel of monoclonal antibodies (mAbs) directed against different epitopes of HLA-II molecules provided by Soldano Ferrone (40) were instrumental for these studies, that were performed in in vitro models of polyclonal T-cell proliferation, induced by either phytohemoagglutinin (PHA) or anti-CD3 mAb (41, 42). Although the presence of antigen presenting cells (APC) was required to achieve full T-cell activation, HLA-II antigen presenting function was largely dispensable in these models, thus offering a unique opportunity to evaluate non-canonical functions of HLA-II molecules.

Giuseppina Ruggiero and Luigi Racioppi in Zappacosta's team, in collaboration with Ciro Manzo, initiated these pioneer studies on HLA-II molecules, and demonstrated that the incubation of autologous monocyte-derived macrophages with mAbs directed against non-polymorphic determinants of HLAII molecules exerted a remarkable inhibitory effect on $\mathrm{T}$ cell activation $(37,38,43)$. This result suggested that MHC-II molecules expressed on the APC could interact not only with the TCR and CD4, but also with additional ligand(s) - at the time unknown-, expressed on the T cell surface. Interestingly, in 1996 one of these hypothetical ligand was identified by Huard et al. (44), who demonstrated the ability of CD223 (aka LAG-3) to bind MHC-II molecules. In the last two decades, the relevance of LAG3/MHC-II signaling has been confirmed by several independent studies, being this molecular interaction involved in a variety of immuno-regulatory circuits (45).

D'Oro and Di Rosa from the Zappacosta's team further explored non-canonical functions of MHC-II molecules expressed by activated human $\mathrm{T}$ cells. These studies were based on the general hypothesis that HLA-II molecules might transduce intracellular signals, and in turn finely tune $\mathrm{T}$ cell response to antigen(s) and cytokines. The results confirmed this possibility, showing that cross-linking of HLA-II on activated $\mathrm{T}$ cells was sufficient to induce inositol triphosphates (IP3) accumulation, protein kinase C (PKC) activation, and, ultimately, enhanced $\mathrm{T}$ cell proliferation $(10,39)$. Of note, the ability of MHC-II molecules to transduce intracellular signals has also been recognized in B cells (46-48), and more recently a cell-intrinsic contribution of MHC-II expression has been shown in the B cell development in the bone marrow (49).
As a note, the findings by Zappacosta's group on noncanonical functions of the HLA molecules have relevant, and still largely unexplored, implications in the regulation of the human immune response. For example, high expression of LAG-3 by T regulatory (Treg) cells suggests that LAG-3/MHC-II complexes might play an important role in the bi-directional signaling triggered by Treg/ $\mathrm{T}$ effector cell interactions $(50,51)$. In this sense, an increasing number of studies has pointed to LAG3/MHC-II interaction as an attractive druggable target to treat autoimmune diseases, stimulate anti-cancer immune response (52), and revert resistance to anti-PD-1 immunotherapy (53).

\section{MHC AND BEYOND}

Giuseppe Matarese devoted his experimental efforts on the innovative hypothesis that nutrient-energy-sensing pathways might represent a powerful tool to control immunological selftolerance. He showed that leptin, a hormone critically involved in energy balance and body weight regulation, acts as a strong immune-modulator, that influences the susceptibility to infection and autoimmunity $(54,55)$. Leptin levels inversely correlated with regulatory $\mathrm{T}$ cell number in multiple sclerosis patients (56), and a direct link between leptin and regulatory $\mathrm{T}$ cell anergy was established (57). This observation, that was further developed in subsequent studies performed by Giuseppe Matarese and his group, in collaboration with Antonio La Cava, was the result of frequent, endless, unforgettable evening lab discussions with Serafino Zappacosta.

After training with Serafino Zappacosta with a focus on the immune-modulating properties of MHC molecules, the team members subsequently developed new hypotheses and investigations in diverse directions, ranging from the study of the fundamental mechanisms of immune regulation and immunological memory, to autoimmunity, cancer immunotherapy and vaccinology (58-66). Serafino Zappacosta kept to enthusiastically follow the progress of the past members of his team after they left to start their independent careers. Many of them remained involved over the years in the Ceppellini School activities, either as faculty members or as components of the board of directors, maintaining the School as an arena of continuous scientific education and dynamic discussion.

\section{CONCLUSIONS}

The review summarizes the legacy left by Serafino Zappacosta to his collaborators who, albeit with different individual perspectives and at a different degree, continued to work on the MHC, looking at these molecules as a window of opportunity to comprehend the complexity of the immune response, rather than merely looking at them as antigen presenting molecules.

After the death of Serafino Zappacosta in 2006, Silvia Fontana became the President of the Ceppellini School, and Ennio Carbone, Giuseppe Matarese, Francesca Di Rosa, Giuseppina Ruggiero, Giuseppe Terrazzano and other previous collaborators of the Zappacosta's team continued to organize advanced international immunology courses, together with the 
long-standing Serafino Zappacosta's collaborators and friends Antonio Di Giacomo, who co-founded the School in 1991 (3), Elizabeth Simpson, who organized the first Ceppellini School Course in 1992 on bone marrow transplantation (67), and the newly recruited Ceppellini School Scientific Director Stefan Kaufmann (68). A new type of event, the Serafino Zappacosta Memorial Conferences, was initiated in 2007. Since 2010, this event has been held in the newly inaugurated "Serafino Zappacosta" Auditorium of the Federico II University of Naples. All these activities were made possible by the excellent work of the Ceppellini School Scientific Secretary Tricia Reynolds.

To conclude, the continuation of the activities of the Ceppellini School not only allows an unceasing engagement of new young bright minds to the fascinating field of immunology, but also keeps alive Serafino Zappacosta's dream that intellectual

\section{REFERENCES}

1. François de Salignac de La Mothe-Fénelon. Les Aventures de Télémaques (1699).

2. La Cava A, De Felice M. In memoriam: Serafino Zappacosta (19352006). Tissue Antigens. (2006) 68:279. doi: 10.1111/j.1399-0039.2006.0 0686.x

3. Di Giacomo A. The Ruggero Ceppellini advanced school of immunology and the neapolitan scientific renaissance. Front Immunol. (2019) 10:1494. doi: 10.3389/fimmu.2019.01494

4. Pinto A, Maio M, Attadia V, Zappacosta S, Cimino R. Modulation of HLA-DR antigens expression in human myeloid leukaemia cells by cytarabine and 5-aza-2'-deoxycytidine. Lancet. (1984) 2:867-8. doi: 10.1016/S0140-6736(84)90900-0

5. Iaffaioli RV, Maio M, Ruggiero G, De Felice M, Ungaro A, Del Vecchio L, et al. HLA and prognostic factors in primary breast cancer. Int J Cancer. (1985) 35:581-5. doi: 10.1002/ijc.2910350503

6. Zappacosta S, Maio M, de Felice M, Valentino R. The association between congenital adrenal hyperplasia and HLA in Southern Italy. Ann N Y Acad Sci. (1985) 458:46-51. doi: 10.1111/j.1749-6632.1985.tb 14589.x

7. Ruggiero G, Cosentini E, Zanzi D, Sanna V, Terrazzano G, Matarese G, et al. Allelic distribution of human leucocyte antigen in historical and recently diagnosed tuberculosis patients in Southern Italy. Immunology. (2004) 111:318-22. doi: 10.1111/j.1365-2567.2004.01811.x

8. Carbone E, Racioppi L, La Cava A, Portella G, Velotti F, Zappacosta S, et al. NK and LAK susceptibility varies inversely with target cell MHC class I antigen expression in a rat epithelial tumour system. Scand J Immunol. (1991) 33:185-94. doi: 10.1111/j.1365-3083.1991.tb03748.x

9. Terrazzano G, Romano M, Turco FM, Salzano CS, Ottaiano A, Venuta S, et al. HLA class I antigen downregulation by interleukin (IL)-10 is predominantly governed by NK-kappaB in the short term and by TAP $1+2$ in the long term. Tissue Antigens. (2000) 55:326-32. doi: 10.1034/j.1399-0039.2000.550406.x

10. D'Oro U, et al. Major Histocompatibility Complex class II molecule transduce activation signal in human T blasts. In: Tsuji K, Aizawa M, and Sasazuki T, editors. HLA 1991, Proceedings of the Eleventh International Histocompatibility Workshop and Conference held in Yokohama, Japan, 6-13 November, 1991. (1992). p. 632-5.

11. Bodmer W. Ruggero Ceppellini: a perspective on his contributions to genetics and immunology. Front Immunol. (2019) 10:1280. doi: 10.3389/fimmu.2019.01280

12. Zappacosta S, De Felice M, Fiore M, Ferrara GB. The HLA system in the Campania region: a genetic study. Tissue Antigens. (1980) 16:286-93. doi: 10.1111/j.1399-0039.1980.tb00308.x freedom can be shared without boundaries for the benefit of younger generations.

\section{AUTHOR CONTRIBUTIONS}

All authors listed have made a substantial, direct and intellectual contribution to the work, and approved it for publication.

\section{DEDICATION}

This article is dedicated to the memory of Luigi Del Vecchio, past member of Zappacosta's team and full professor of Clinical Biochemistry and Molecular Biology, Dipartimento di Medicina Molecolare e Biotecnologie Mediche, Università degli Studi di Napoli "Federico II," Naples, Italy at the time of his premature death in 2018.

13. Piazza A, Menozzi P, Cavalli-Sforza LL. The HLA-A,B gene frequencies in the world: migration or selection. Hum Immunol. (1980) 1:297-304. doi: 10.1016/0198-8859(80)90105-6

14. Montanaro D, Sanna V, Matarese G, Larby BB, Racioppi L, Carrieri PB, et al. The fine specificity of human $\mathrm{T}$ cell lines towards myelin basic protein peptides in southern Italian multiple sclerosis patients. Clin Exp Immunol. (2001) 123:288-93. doi: 10.1046/j.1365-2249.2001.01457.x

15. Panza N, Del Vecchio L, Maio M, De Felice M, Lombardi G, Minozzi M, et al. Strong association between an HLA-DR antigen and thyroid carcinoma. Tissue Antigens. (1982) 20:155-8. doi: 10.1111/j.1399-0039.1982.tb00340.x

16. Fontana S, Del Vecchio L, Racioppi L, Carbone E, Pinto A, Colletta G, et al. Expression of major histocompatibility complex class I antigens in normal and transformed rat thyroid epithelial cell lines. Cancer Res. (1987) 47:4178-83.

17. Racioppi L, Carbone E, Grieco M, Del Vecchio L, Berlingieri MT, Fusco A, et al. The relationship of modulation of major histocompatibility complex class I antigens to retrovirus transformation in rat cell lines. Cancer Res. (1988) 48:3816-21.

18. Bjorkman PJ, Saper MA, Samraoui B, Bennett WS, Strominger JL, Wiley DC. The foreign antigen binding site and $\mathrm{T}$ cell recognition regions of class $\mathrm{I}$ histocompatibility antigens. Nature. (1987) 329:512-8. doi: 10.1038/329512a0

19. Bjorkman PJ, Saper MA, Samraoui B, Bennett WS, Strominger JL, Wiley DC. Structure of the human class I histocompatibility antigen, HLA-A2. Nature. (1987) 329:506-12. doi: 10.1038/329506a0

20. Karre K. Natural killer cell recognition of missing self. Nat Immunol. (2008) 9:477-80. doi: 10.1038/ni0508-477

21. La Cava A, Carbone E, Moscarella A, Barcova M, Salzano S, Zappacosta $\mathrm{S}$, et al. A novel strategy of c-myc oncogene in NK activity regulation not related to the W6/32 MHC class-I epitope. Int J Cancer. (1994) 58:123-8. doi: 10.1002/ijc.2910580120

22. Carbone E, Terrazzano G, Colonna M, Tuosto L, Piccolella E, Franksson L, et al. Natural killer clones recognize specific soluble HLA class I molecules. Eur J Immunol. (1996) 26:683-9. doi: 10.1002/eji.1830260326

23. Carbone E, Ruggiero G, Terrazzano G, Palomba C, Manzo C, Fontana S, et al. A new mechanism of NK cell cytotoxicity activation: the CD40-CD40 ligand interaction. J Exp Med. (1997) 185:2053-60. doi: 10.1084/jem.185.12.2053

24. Carbone E, Terrazzano G, Ruggiero G, Zanzi D, Ottaiano A, Manzo C, et al. Recognition of autologous dendritic cells by human NK cells. Eur J Immunol. (1999) 29:4022-9. doi: 10.1002/(SICI)1521-4141(199912)29:12<4022::AIDIMMU4022>3.0.CO;2-O

25. Terrazzano G, Pisanti S, Grimaldi S, Sica M, Fontana S, Carbone E, et al. Interaction between natural killer and dendritic cells: the role of CD40, CD80 and major histocompatibility complex class i molecules in cytotoxicity induction and interferon-gamma production. Scand J Immunol. (2004) 59:356-62. doi: 10.1111/j.0300-9475.2003.01387.x 
26. Carbone E, Terrazzano G, Melián A, Zanzi D, Moretta L, Porcelli S, et al. Inhibition of human NK cell-mediated killing by CD1 molecules. J Immunol. (2000) 164:6130-7. doi: 10.4049/jimmunol.164.12.6130

27. Terrazzano G, Sica M, Gianfrani C, Mazzarella G, Maurano F, De Giulio B, et al. Gliadin regulates the NK-dendritic cell cross-talk by HLA-E surface stabilization. J Immunol. (2007) 179:372-81. doi: 10.4049/jimmunol.179.1.372

28. Germain RN. Immunology. The ins and outs of antigen processing and presentation. Nature. (1986) 322:687-9. doi: 10.1038/322687a0

29. Braciale TJ, Morrison LA, Sweetser MT, Sambrook J, Gething MJ, Braciale VL. Antigen presentation pathways to class I and class II MHC-restricted T lymphocytes. Immunol Rev. (1987) 98:95-114. doi: 10.1111/j.1600-065X.1987.tb00521.x

30. Fremont DH, Matsumura M, Stura EA, Peterson PA, Wilson IA. Crystal structures of two viral peptides in complex with murine MHC class I H-2Kb. Science. (1992) 257:919-27. doi: 10.1126/science.1323877

31. Zhang W, Young AC, Imarai M, Nathenson SG, Sacchettini JC. Crystal structure of the major histocompatibility complex class I H-2Kb molecule containing a single viral peptide: implications for peptide binding and T-cell receptor recognition. Proc Natl Acad Sci USA. (1992) 89:8403-7. doi: 10.1073/pnas.89.17.8403

32. Madden DR, Gorga JC, Strominger JL, Wiley DC. The threedimensional structure of HLA-B27 at $2.1 \mathrm{~A}$ resolution suggests a general mechanism for tight peptide binding to MHC. Cell. (1992) 70:1035-48. doi: 10.1016/0092-8674(92)90252-8

33. Silver ML, Guo HC, Strominger JL, Wiley DC. Atomic structure of a human MHC molecule presenting an influenza virus peptide. Nature. (1992) 360:3679. doi: $10.1038 / 360367 \mathrm{a} 0$

34. Stern LJ, Brown JH, Jardetzky TS, Gorga JC, Urban RG, Strominger JL, et al. Crystal structure of the human class II MHC protein HLA-DR1 complexed with an influenza virus peptide. Nature. (1994) 368:215-21. doi: $10.1038 / 368215 \mathrm{a} 0$

35. Jardetzky TS, Brown JH, Gorga JC, Stern LJ, Urban RG, Chi YI, et al. Three-dimensional structure of a human class II histocompatibility molecule complexed with superantigen. Nature. (1994) 368:711-8. doi: $10.1038 / 368711 \mathrm{a} 0$

36. Ruggiero G, Manzo C, Fontana S, Scala G, Pirozzi G, Ferrone S, et al. Inhibition by anti-HLA class II monoclonal antibodies of monocytedependent T cell proliferation induced by monoclonal antibody OKT3. Eur J Immunol. (1987) 17:1585-92. doi: 10.1002/eji.1830171110

37. Racioppi L, Moscarella A, Ruggiero G, Manzo C, Ferrone S, Fontana S, et al. Inhibition by anti-HLA class II monoclonal antibodies of monoclonal antibody OKT3-induced T cell proliferation. Studies at the mRNA level. $J$ Immunol. (1990) 145:3635-40.

38. Ruggiero G, Racioppi L, Manzo C, Pirozzi G, D’Oro U, Ferrone S, et al. HLA class II molecules on monocytes regulate $\mathrm{T}$ cell proliferation through physical interaction in the CD3 activation pathway. Eur J Immunol. (1991) 21:29-33. doi: 10.1002/eji.1830210106

39. Di Rosa F, D’Oro U, Ruggiero G, Racioppi L, Acquaviva A, Ferrone S, et al. HLA class II molecules transduce accessory signals affecting the CD3 but not the interleukin-2 activation pathway in T blasts. Hum Immunol. (1993) 38:251-60. doi: 10.1016/0198-8859(93)90552-C

40. Quaranta V, Pellegrino MA, Ferrone S. Serologic and immunochemical characterization of the specificity of four monoclonal antibodies to distinct antigenic determinants expressed on subpopulations of human Ia-like antigens. J Immunol. (1981) 126:548-52.

41. Gallagher RB, Cambier JC. Signal transmission pathways and lymphocyte function. Immunol Today. (1990) 11:187-9. doi: 10.1016/0167-5699(90)90078-N

42. Samelson LE, Fletcher MC, Ledbetter JA, June CH. Activation of tyrosine phosphorylation in human $\mathrm{T}$ cells via the CD2 pathway. Regulation by the CD45 tyrosine phosphatase. J Immunol. (1990) 145:2448-54.

43. Manzo C, Ruggiero G, del Vecchio L, Racioppi L, Pirozzi G, Temponi $\mathrm{M}$, et al. Monoclonal antibody OKT3-induced $\mathrm{T}$ cell proliferation: differential role of HLA class II determinants expressed by $\mathrm{T}$ cells and monocytes. Cell Immunol. (1990) 125:79-91. doi: 10.1016/0008-8749(90)9 0064-X

44. Huard B, Prigent P, Pages F, Bruniquel D, Triebel F. T cell major histocompatibility complex class II molecules down-regulate CD4 $+\mathrm{T}$ cell clone responses following LAG-3 binding. Eur J Immunol. (1996) 26:1180-6. doi: 10.1002/eji.1830260533

45. Lui Y, Davis SJ. LAG-3: a very singular immune checkpoint. Nat Immunol. (2018) 19:1278-9. doi: 10.1038/s41590-018-0257-1

46. Wade WF, Davoust J, Salamero J, Andre P, Watts TH, Cambier JC. Structural compartmentalization of MHC class II signaling function. Immunol Today. (1993) 14:539-46. doi: 10.1016/0167-5699(93)90184-M

47. Al-Daccak R, Mooney N, Charron D. MHC class II signaling in antigen-presenting cells. Curr Opin Immunol. (2004) 16:108-13. doi: 10.1016/j.coi.2003.11.006

48. Harton J, Jin L, Hahn A, Drake J. Immunological functions of the membrane proximal region of MHC class II molecules. F1000Res. (2016) 5:1-12. doi: 10.12688/f1000research.7610.1

49. Merkenschlager J, Eksmond U, Danelli L, Attig J, Young G, R, Nowosad C, et al. MHC class II cell-autonomously regulates self-renewal and differentiation of normal and malignant B cells. Blood. (2019) 133:1108-18. doi: 10.1182/blood-2018-11-885467

50. Zhang Q, Chikina M, Szymczak-Workman AL, Horne W, Kolls JK, Vignali KM, et al. LAG3 limits regulatory $\mathrm{T}$ cell proliferation and function in autoimmune diabetes. Sci Immunol. (2017) 2:eaah4569. doi: 10.1126/sciimmunol.aah4569

51. Thaker Y, Andrews LP, Workman CJ, Vignali DAA, Sharpe AH. Treg-specific LAG3 deletion reveals a key role for LAG3 in regulatory T cells to inhibit CNS autoimmunity. J Immunol. (2018) 200:101.7.

52. Shapiro M, Herishanu Y, Katz BZ, Dezorella N, Sun C, Kay S, et al. Lymphocyte activation gene 3: a novel therapeutic target in chronic lymphocytic leukemia. Haematologica. (2017) 102:874-82. doi: 10.3324/haematol.2016.148965

53. Long L, Zhang X, Chen F, Pan Q, Phiphatwatchara P, Zeng Y, et al. The promising immune checkpoint LAG-3: from tumor microenvironment to cancer immunotherapy. Genes Cancer. (2018) 9:176-89. doi: 10.18632/genesandcancer.180

54. Lord GM, Matarese G, Howard JK, Baker RJ, Bloom SR, Lechler RI. Leptin modulates the T-cell immune response and reverses starvation-induced immunosuppression. Nature. (1998) 394:897-901. doi: 10.1038/29795

55. Sanna V, Di Giacomo A, La Cava A, Lechler RI, Fontana S, Zappacosta $S$, et al. Leptin surge precedes onset of autoimmune encephalomyelitis and correlates with development of pathogenic $\mathrm{T}$ cell responses. J Clin Invest. (2003) 111:241-50. doi: 10.1172/JCI200316721

56. Matarese G, Carrieri PB, La Cava A, Perna F, Sanna V, De Rosa V, et al. Leptin increase in multiple sclerosis associates with reduced number of CD4(+)CD25+ regulatory T cells. Proc Natl Acad Sci USA. (2005) 102:51505. doi: 10.1073/pnas.0408995102

57. De Rosa V, Procaccini C, Calì G, Pirozzi G, Fontana S, Zappacosta S, et al. A key role of leptin in the control of regulatory $\mathrm{T}$ cell proliferation. Immunity. (2007) 26:241-55. doi: 10.1016/j.immuni.2007.01.011

58. Silberschmidt D, Rodriguez-Mallon A, Mithboakar P, Calì G, Amendola E, Sanges $\mathrm{R}$, et al. In vivo role of different domains and of phosphorylation in the transcription factor Nkx2-1. BMC Dev Biol. (2011) 11:9. doi: 10.1186/1471-213X-11-9

59. Procaccini C, Carbone F, Di Silvestre D, Brambilla F, De Rosa V, Galgani M, et al. The proteomic landscape of human ex vivo regulatory and conventional $\mathrm{T}$ cells reveals specific metabolic requirements. Immunity. (2016) 44:712. doi: 10.1016/j.immuni.2016.02.022

60. Ali TH, Pisanti S, Ciaglia E, Mortarini R, Anichini A, Garofalo C, et al Enrichment of CD56(dim)KIR + CD57 + highly cytotoxic NK cells in tumour-infiltrated lymph nodes of melanoma patients. Nat Commun. (2014) 5:5639. doi: $10.1038 /$ ncomms6639

61. Racioppi L, Nelson ER, Huang W, Mukherjee D, Lawrence SA, Lento W, et al. CaMKK2 in myeloid cells is a key regulator of the immune-suppressive microenvironment in breast cancer. Nat Commun. (2019) 10:2450. doi: 10.1038/s41467-019-10 424-5

62. Tulli L, Cattaneo F, Vinot J, Baldari CT, D’Oro U. Src family kinases regulate interferon regulatory factor 1 K63 ubiquitination following activation by TLR7/8 vaccine adjuvant in human monocytes and B cells. Front Immunol. (2018) 9:330. doi: 10.3389/fimmu.2018. 00330 
63. Di Rosa F. Maintenance of memory $\mathrm{T}$ cells in the bone marrow: survival or homeostatic proliferation? Nat Rev Immunol. (2016) 16:271. doi: $10.1038 /$ nri.2016.31

64. Di Giacomo AM, Covre A, Finotello F, Rieder D, Danielli R, Sigalotti L, et al. Guadecitabine plus ipilimumab in unresectable melanoma: the NIBIT-M4 clinical trial. Clin Cancer Res. (2019) 25:7351-62. doi: 10.1158/1078-0432.CCR-19-1335

65. Liu Y, Liu A, Iikuni N, Xu H, Shi FD, La Cava A. Regulatory CD4+ T cells promote B cell anergy in murine lupus. J Immunol. (2014) 192:4069-73. doi: 10.4049/jimmunol.1302897

66. Giovazzino A, Leone S, Rubino V, Palatucci AT, Cerciello G, Alfinito F, et al. Reduced regulatory $\mathrm{T}$ cells (Treg) in bone marrow preferentially associate with the expansion of cytotoxic T lymphocytes in low risk MDS patients. $\mathrm{Br} J$ Haematol. (2019) 185:357-60. doi: 10.1111/bjh.15496

67. Simpson E, Dazzi F. Bone marrow transplantation 1957-2019. Front Immunol. (2019) 10:1246. doi: 10.3389/fimmu.2019.01246

68. Kaufmann SHE. Immunology's coming of age. Front Immunol. (2019) 10:684. doi: 10.3389/fimmu.2019.01214
Conflict of Interest: UD is an employee of the GSK group of companies and holds restricted shares of the GSK group of companies.

The remaining authors declare that the research was conducted in the absence of any commercial or financial relationships that could be construed as a potential conflict of interest.

The reviewer DB declared a shared affiliation, with no collaboration, with several of the authors, MD, FDR, SF, to the handling editor at time of review.

Copyright (C) 2020 Carbone, De Felice, Di Rosa, D’Oro, Fontana, La Cava, Maio, Matarese, Racioppi, Ruggiero and Terrazzano. This is an open-access article distributed under the terms of the Creative Commons Attribution License (CC BY). The use, distribution or reproduction in other forums is permitted, provided the original author(s) and the copyright owner(s) are credited and that the original publication in this journal is cited, in accordance with accepted academic practice. No use, distribution or reproduction is permitted which does not comply with these terms. 